\title{
Interleukin-35 is associated with the tumorigenesis and progression of prostate cancer
}

\author{
JIALIN ZHU ${ }^{1 *}$, XUELING YANG ${ }^{2 *}, Y^{*}$ WANG $^{2}$, HAONAN ZHANG $^{2}$ and ZHI GUO ${ }^{2}$ \\ Departments of ${ }^{1}$ Ultrasound Diagnosis and Treatment, and ${ }^{2}$ Interventional Therapy, Tianjin Medical University \\ Cancer Institute and Hospital, National Clinical Research Center for Cancer, Key Laboratory of Cancer Prevention \\ and Therapy, Tianjin's Clinical Research Center for Cancer, Tianjin 300060, P.R. China
}

Received October 30, 2018; Accepted March 4, 2019

DOI: $10.3892 / \mathrm{ol} .2019 .10208$

\begin{abstract}
Interleukin (IL)-35 is a novel member of the IL-12 cytokine family, which exhibits a unique immune regulatory function. Previously, it was demonstrated that IL-35 expression is significantly increased in a wide range of tumor tissues, promoting angiogenesis and inhibiting the anti-tumor immune response. In the present study, the IL-35 protein expression levels were measured in the plasma and tumor tissue of patients with prostate cancer (PCA), and its role was determined in the occurrence and progression of PCA. Plasma IL-35 expression levels were measured using ELISA, and the associations of plasma IL-35 and clinicopathological parameters were analyzed. Receiver operating characteristic curves were plotted to analyze the role of IL-35 as a clinical biomarker for the diagnosis of PCA. Survival curve analysis demonstrated a significant decrease in the survival time in months in patients with PCA and increased expression levels of IL-35 compared with the participants with relatively lower IL-35 protein expression levels. IL-35 expression was detected using immunohistochemical staining of a human PCA tissue microarray. Plasma IL-35 expression levels in the patients with PCA were significantly increased compared with the patients with benign prostatic hyperplasia and the healthy controls. An increase in the plasma concentration of IL-35 was associated with progression of PCA stage and an increase in the Gleason score. Significant differences in AUCs for IL-35 and prostate-specific antigen were observed with regard to the presence of lymph node and distant metastases in patients
\end{abstract}

Correspondence to: Dr Zhi Guo, Department of Interventional Therapy, Tianjin Medical University Cancer Institute and Hospital, National Clinical Research Center for Cancer, Key Laboratory of Cancer Prevention and Therapy, Tianjin's Clinical Research Center for Cancer, 9 Huan Hu West Road, Tianjin 300060, P.R. China E-mail: cjr.guozhi@vip.163.com

${ }^{*}$ Contributed equally

Key words: cytokine, interleukin-35, prostate cancer, prostate cancer progression, prostate cancer metastasis with PCA. The expression levels of Epstein-barr virus-induced gene 3 (EBI3) and IL-12A (p35; the subunits which together form IL-35) were significantly increased in the tumor tissue compared with the adjacent normal tissue. An association was identified between the Gleason score and the expression of EBI3 and p35. Therefore, increased expression of IL-35 in the plasma and tumor tissues may contribute to the progression and metastasis of PCA, and IL-35 may serve as a novel prognostic biomarker or therapeutic target for the treatment of PCA.

\section{Introduction}

Prostate cancer (PCA) is the second most common malignant tumor following lung cancer and the fifth leading cause of cancer-associated mortality in men worldwide (1). Prostate-specific antigen (PSA) is the most widely used tumor marker for PCA in early diagnosis and treatment evaluation (2). However, PSA is not cancer specific; instead it is an organ-specific marker. Benign prostatic hyperplasia $(\mathrm{BPH})$, prostatic intraepithelial neoplasia, acute and chronic prostatitis, and other non-malignant prostate diseases may additionally lead to elevated plasma PSA expression levels $(3,4)$. Such a relatively low specificity may lead to a false positive diagnosis in $\leq 65 \%$ of patients, if only the plasma expression level of PSA was used to distinguish PCA from benign diseases (4). In addition, there is a weak correlation between PSA expression levels and PCA severity, which undermines the use of PSA in disease grading (5). At present, prostate biopsies are necessary; however, it is an invasive method for precise diagnosis in clinical practice. Therefore, more specific and reliable biomarkers are required for the detection, diagnosis and prognosis of PCA.

Interleukin (IL)-35 is a member of the IL-12 cytokine family, which possesses a unique immune regulatory function. IL-35 is composed of an Epstein-barr virus-induced gene 3 (EBI3) subunit and IL-12A (p35) subunit (6). Previous studies demonstrated that IL-35 expression was increased in a variety of tumor tissues, including pancreatic ductal adenocarcinoma (PDAC), colorectal cancer, renal cell carcinoma and laryngeal squamous cell cancer (7-10). Furthermore, IL-35 was demonstrated to promote tumor angiogenesis and inhibit the anti-tumor cytotoxic lymphocyte response (11). Additionally, IL-35 protein expression levels in the plasma are associated with tumor stages, tumor size and the presence of adjacent 
lymph node metastasis in various types of cancer, including PDAC and breast cancer $(12,13)$, suggesting that IL-35 may be associated with tumor progression. Increased expression of IL-35 in tumor tissues and increased expression levels in the plasma were associated with a poor prognosis in a number of malignancies, including acute myeloid leukemia, lung cancer, hepatocellular carcinoma and gastric cancer (14-17).

At present, the expression patterns and functions of IL-35 in PCA have not been studied extensively, to the best of the authors' knowledge. Therefore, in the present study, plasma IL-35 protein expression levels in the peripheral blood and tumor tissues of patients with PCA were examined, and the association between the expression of IL-35 and the clinicopathological characteristics of PCA was analyzed, to examine the potential involvement of IL-35 in the progression of PCA.

\section{Patients and methods}

Patients and specimens. A total of 66 men with PCA [mean age \pm standard deviation (SD), $65.07 \pm 7.78$ years], and 66 age-matched men with $\mathrm{BPH}$ who were referred to The Tianjin Medical University Cancer Hospital (Tianjin, China), between January 2013 and June 2014 were recruited. The patients with PCA were enrolled in the present study prior to receiving radiotherapy, chemotherapy or immunotherapy. In addition, 56 healthy men, who visited The Tianjin Medical University Cancer Hospital, were involved in the present study. The healthy men were without acute or chronic diseases or any evidence of malignancies. Individuals who smoked, were taking prescribed medication, had a history of recurrent infections, asthma, allergies or atopic diseases, or any other suspected immunological diseases, were all excluded from the present study.

According to the medical records and pathological reports, the existence of PCA was confirmed by surgery or needle biopsy. The Tumor-Node-Metastasis (TNM) stage and clinical stage of PCA were based on the principles for the Eighth Edition of the American Joint Committee on Cancer TNM Staging Manual (18). The Gleason score was based on An Update with Discussion on Practical Issues to Implement the 2014 International Society of Urological Pathology Consensus Conference on Gleason Grading of Prostatic Carcinoma (19). Levels of PSA expression were obtained from the patient medical records. The present study was approved by The Ethics Committee of the Tianjin Medical University Cancer Institute and Hospital. All participants were recruited subsequent to providing written informed consent. A $5 \mathrm{ml}$ specimen of peripheral blood was obtained from all the individuals, and the plasma was separated and stored at $-80^{\circ} \mathrm{C}$ for analysis.

Measurement of the IL-35 concentration. The IL-35 concentration in the plasma was measured using a human IL-35 ELISA kit (catalog no. SEC008Hu; Cloud-Clone Corp., Katy, TX, USA) according to the manufacturer's protocol. Each sample was assayed three times. The minimum detectable dose of this kit is typically $<5.8 \mathrm{pg} / \mathrm{ml}$.

Human tumor specimens and immunohistochemical staining. Human paraffin embedded tissue microarrays (ProA180PG04; 90 cases/180 points) were ordered from Shanghai Outdo Biotech Co. Ltd. (Shanghai, China). For the tissue microarray $1.5-\mathrm{mm}$ core samples were used, and the thickness of the sections was $4 \mu \mathrm{m}$. The major regents used were as follows: i) 10X PBS buffer (formula: $80 \mathrm{~g} \mathrm{NaCl}, 2 \mathrm{~g} \mathrm{KCl}$, $15.35 \mathrm{~g} \mathrm{Na}_{2} \mathrm{HPO}_{4}, 2 \mathrm{~g} \mathrm{KH}_{2} \mathrm{PO}_{4}$, dissolved with deionized water up to 1 liter, $\mathrm{pH}$ 7.2). For $1 \mathrm{X}$ PBS buffer, the 10X PBS buffer was diluted and the Tween reagents $(0.05 \%$ of total volume) were added; ii) citric acid solution: $0.1 \mathrm{~mol} / 1$ sodium citrate solution $(82 \mathrm{ml}), 0.1 \mathrm{~mol} / \mathrm{l}$ citric acid solution $(18 \mathrm{ml})$, deionized water $(900 \mathrm{ml})(\mathrm{pH} 6.0)$; and iii) peroxidase-blocking reagent: $38.4 \mathrm{ml}$ anhydrous methanol, $12 \mathrm{ml} 30 \% \mathrm{H}_{2} \mathrm{O}_{2}$ and $9.6 \mathrm{ml} \mathrm{ddH_{2 }}$ O. The tissue microarray was incubated in a dry oven at $63^{\circ} \mathrm{C}$ for $1 \mathrm{~h}$. The de-paraffinization and rehydration processes were performed at room temperature. The slides were washed twice for $15 \mathrm{~min}$ each time with Xylene and subsequently washed twice for $7 \mathrm{~min}$ with absolute ethanol. Finally, the slides were washed for 5 min with 90,80 and $70 \%$ ethanol, respectively. Subsequently, the slides were rinsed 3 times, for 1 min each time, with deionized water. Citric acid high-pressure repair was used for antigen retrieval and the slides were bathed in peroxidase-blocking reagent for $15 \mathrm{~min}$ at room temperature. The sections were blocked with $3 \% \mathrm{BSA}$ (Beijing Solarbio Science and Technology Co., Ltd., Beijing, China; cat. no. A8020), incubated with mouse anti-human p35 antibody (Abcam, Cambridge, UK; cat. no. ab66064; 1:100) and rabbit anti-EBI3 antibody (Abcam; cat. no. ab83896; 1:100) overnight at $4^{\circ} \mathrm{C}$ in a humidified chamber, and subsequently incubated with horseradish peroxidase-conjugated secondary antibodies (Abcam; cat. nos. ab97046 and ab6721; $1: 800$ ) at room temperature for $30 \mathrm{~min}$. Finally, expression was visualized with 3,3-diaminobenzidine (DAB) and Mayer's hematoxylin staining. The slides were incubated with DAB solution for $5 \mathrm{~min}$ and bathed for $40 \mathrm{sec}$ in Mayer's hematoxylin solution, both at room temperature. The Leica scanscope XT (Leica Microsystems, Wetzlar, Germany) was used to capture the images (magnification $\mathrm{x} 40$ and $\mathrm{x} 200$ ). The intensity score was evaluated blindly by 3 independent observers using the following scoring system: i) Negative, 0 ; ii) weak, 1; moderate, 2; and iii) strong, 3. The extent score was defined as: i) Negative, 0 ; ii) $<25 \%$ positive, 1 ; iii) $25-50 \%$ positive, 2 ; iv) $51-75 \%$ positive, 3 ; and v) $>75 \%$ positive, 4 . The final score was calculated by multiplying the scores of the intensity by the extent and dividing the samples into four grades: i) Negative, 0, (-); ii) low staining, 1-3, (+); iii) medium staining, 4-7, (++); and iv) high staining, 8-12, (+++).

Statistical analysis. Statistical analyses were performed using SPSS 23.0 (IBM Corp., Armonk, NY, USA) or GraphPad Prism 7 (GraphPad Software, Inc., La Jolla, CA, USA). Data are presented as the mean $\pm \mathrm{SD}$. A one-way analysis of variance was used, followed by the least significant difference post hoc test, to determine the statistical significance of differences between the clinicopathological characteristics of the PCA, $\mathrm{BPH}$ and healthy control groups. Continuous variables were measured using a Kolmogorov-Smirnov test and a Student's t-test was used to test parametric data. $\mathrm{P}<0.05$ was considered to indicate a statistically significant difference. A receiver operating characteristic (ROC) curve was plotted and the area under the curve (AUC) was calculated to compare the predictive value of each independent variable. Kaplan-Meier survival curves were analyzed for relevant variables. A log-rank test 
Table I. Clinical characteristics of patients with PCA, patients with BPH and the HC group.

\begin{tabular}{|c|c|c|c|c|c|}
\hline Characteristic & PCA & $\mathrm{BPH}$ & $\mathrm{HC}$ & $\mathrm{F}$ & P-value \\
\hline $\mathrm{n}$ & 66 & 66 & 56 & & \\
\hline Age, years & $67.26 \pm 8.64$ & $68.95 \pm 7.58$ & $69.30 \pm 10.71$ & 2.805 & 0.0631 \\
\hline $\mathrm{PSA}, \mu \mathrm{g} / 1$ & $44.81 \pm 37.06$ & $9.92 \pm 10.41$ & $1.40 \pm 1.39$ & 63.950 & $<0.0001^{\mathrm{a}}$ \\
\hline IL-35, pg/ml & $127.49 \pm 52.07$ & $54.59 \pm 33.71$ & $42.88 \pm 20.77$ & 91.160 & $<0.0001^{\mathrm{a}}$ \\
\hline
\end{tabular}

Data are presented as the mean \pm standard deviation. ${ }^{\mathrm{a}} \mathrm{P}<0.001$. PCA, prostate cancer; IL-35, interleukin-35; BPH, benign prostatic hyperplasia; $\mathrm{HC}$, healthy control; PSA, prostate-specific antigen.

A

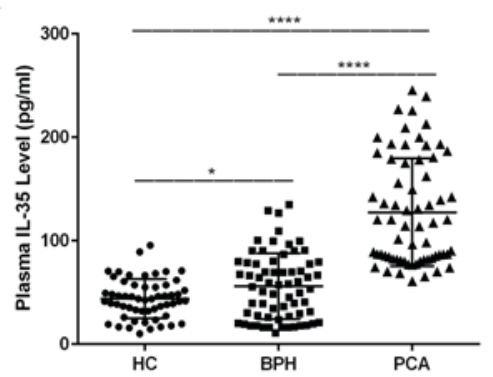

D

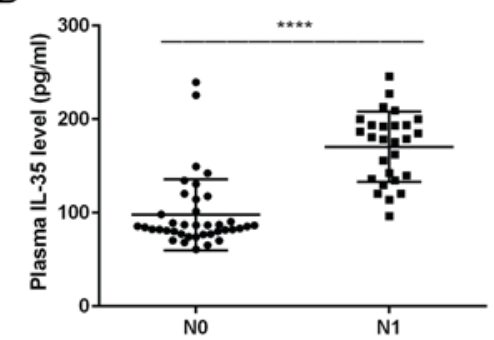

B

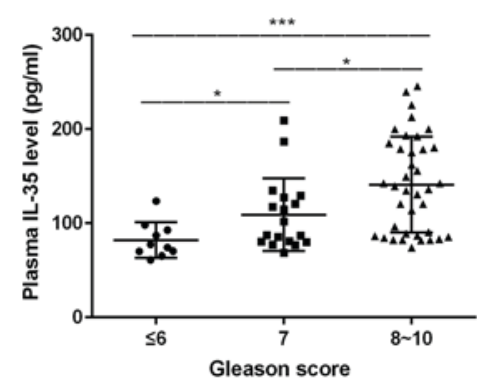

E

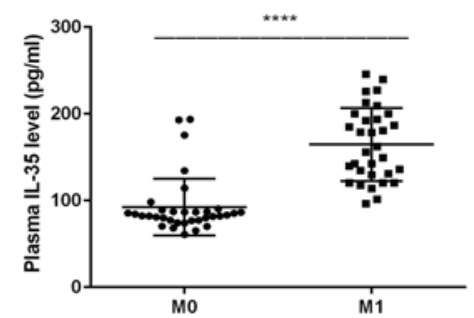

C

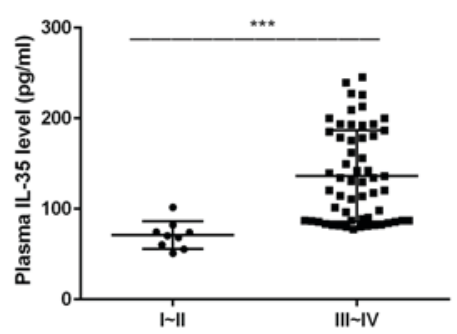

$\mathrm{F}$

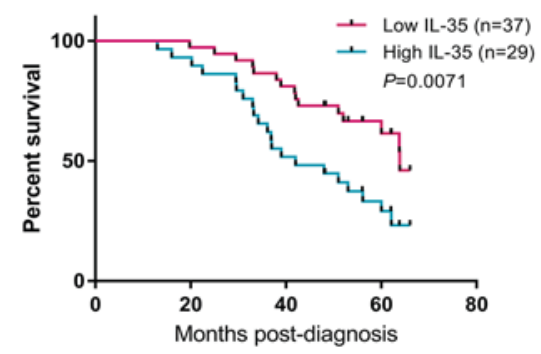

Figure 1. Plasma IL-35 concentration and clinicopathological characteristics of patients with PCA. (A) Plasma IL-35 concentration among patients with either PCA or BPH and the HC group. ${ }^{*} \mathrm{P}<0.05$ and $^{* * * * *} \mathrm{P}<0.0001$. (B) Plasma IL-35 concentration among of patients with different Gleason scores. ${ }^{*} \mathrm{P}<0.05$ and ${ }^{* * *} \mathrm{P}<0.001$. (C) Plasma IL-35 concentration among of patients with different Tumor-Node-Metastasis stages. ${ }^{* * *} \mathrm{P}<0.001$. (D) Plasma IL-35 concentration of patients with or without lymph node metastasis. ${ }^{* * * *} \mathrm{P}<0.0001$. (E) Plasma IL-35 concentration of patients with or without distant metastasis. ${ }^{* * * *} \mathrm{P}<0.0001$. (F) Overall survival rate of patients with PCA with a high or low plasma IL-35 concentration. P=0.0071. IL-35, interleukin-35; PCA, prostate cancer; BPH, benign prostatic hyperplasia; HC; healthy control; N0, negative for lymph node metastasis; N1, positive for lymph node metastasis; M0, negative for distant metastasis; M1, positive for distant metastasis.

was used to analyze the differences in survival times amongst different groups. A Spearman's rank correlation coefficient test was used to test the correlation of EBI3 and p35 in patients with PCA.

\section{Results}

General characteristics of the participants. The clinical and pathological features of the enrolled subjects are summarized in Table $\mathrm{I}$. The mean age $\pm \mathrm{SD}$ of each group was as follows: Patients with PCA, 67.26 \pm 8.64 years; patients with $\mathrm{BPH}, 68.95 \pm 7.58$ years; and the healthy control group, $69.30 \pm 10.71$ years (Table $\mathrm{I} ; \mathrm{P}=0.0631$ ). The plasma PSA expression levels in the patients with PCA, patients with $\mathrm{BPH}$ and the HC group were 44.81 $\pm 37.06,9.92 \pm 10.41$ and $1.40 \pm 1.39 \mu \mathrm{g} / 1$, respectively, and the plasma PSA expression levels were significantly different across all three groups
(Table I; P<0.0001). The mean PSA level in the plasma of patients with PCA was significantly higher compared with that in patients with BPH and in the healthy control group $(\mathrm{P}<0.001)$. However, there was no significant difference in the plasma PSA levels between patients with BPH and the healthy control group (Table I; $\mathrm{P}=0.432$ ).

IL-35 plasma concentration in patients with PCA and BPH, and healthy controls. The mean IL-35 plasma concentration of the three groups was significantly different $(\mathrm{P}<0.0001)$. The mean IL-35 plasma concentration was significantly increased in patients with PCA compared with the patients with $\mathrm{BPH}$ $(127.49 \pm 52.07$ vs. $54.59 \pm 33.71 \mathrm{pg} / \mathrm{ml}$, respectively; $\mathrm{P}<0.0001$; Table I). Similarly, the mean IL-35 plasma concentration in the patients with BPH was significantly increased compared with the healthy control group $(54.59 \pm 33.71$ vs. $42.88 \pm 20.77 \mathrm{pg} / \mathrm{ml}$; $\mathrm{P}=0.0137$; Table I; Fig. 1A). The level of IL-35 in the PCA 
Table II. Demographic data and plasma expression levels of IL-35 in patients with prostate cancer according to different clinical and pathological characteristics.

\begin{tabular}{|c|c|c|c|c|}
\hline Variables & Number of cases & $\mathrm{IL}-35, \mathrm{pg} / \mathrm{ml}$ & $\mathrm{t} / \mathrm{F}$ value & P-value \\
\hline Age, years & & & 0.717 & 0.477 \\
\hline$\geq 65$ & 41 & $123.88 \pm 45.73$ & & \\
\hline$<65$ & 25 & $134.09 \pm 61.55$ & & \\
\hline $\mathrm{PSA}, \mu \mathrm{g} / 1$ & & & 2.896 & $0.01^{\mathrm{a}}$ \\
\hline$\geq 10$ & 56 & $133.37 \pm 52.52$ & & \\
\hline$<10$ & 10 & $94.55 \pm 36.13$ & & \\
\hline Gleason score & & & $\mathrm{F}=8.202$ & $0.0007^{\mathrm{b}}$ \\
\hline$\leq 6$ & 10 & $82.07 \pm 18.92$ & & \\
\hline 7 & 18 & $109.12 \pm 38.67$ & & \\
\hline $8-10$ & 38 & $141.05 \pm 51.07$ & & \\
\hline TNM stage & & & 3.831 & $0.0003^{\mathrm{b}}$ \\
\hline $\mathrm{I}-\mathrm{II}$ & 9 & $70.87 \pm 15.26$ & & \\
\hline III-IV & 57 & $136.26 \pm 50.54$ & & \\
\hline Lymph node metastasis & & & 7.672 & $<0.000^{\mathrm{b}}$ \\
\hline Yes & 27 & $170.48 \pm 37.49$ & & \\
\hline No & 39 & $97.73 \pm 38.14$ & & \\
\hline Distant metastasis & & & 7.784 & $<0.000^{\mathrm{b}}$ \\
\hline Yes & 32 & $164.64 \pm 42.15$ & & \\
\hline No & 34 & $92.53 \pm 32.77$ & & \\
\hline
\end{tabular}

Data are presented as the mean \pm standard deviation; ${ }^{a} \mathrm{P}<0.05$ and ${ }^{\mathrm{b}} \mathrm{P}<0.001$. IL-35, interleukin-35, TNM, Tumor-Node-Metastasis; PSA, prostate-specific antigen.

group was significantly higher compared with that in the healthy control group $(127.49 \pm 52.07$ vs. $42.88 \pm 20.77 \mathrm{pg} / \mathrm{ml}$; $\mathrm{P}<0.0001$; Table I; Fig. 1A).

Classification of patients with PCA. The patients with PCA were classified into three groups: Gleason score of $\leq 6, n=10$; score 7, $n=18$; and score $8-10, n=38$ (Table II). The patients with PCA were distributed according to their TNM stages with 9 patients in stage I or II, and 57 patients in stage III or IV (Table II). There were 27 patients with PCA with lymph node metastasis, compared with 39 patients without lymph node metastasis. Additionally, there were 32 patients with PCA with distant metastasis, including bone or lung metastasis compared with 34 patients without distant metastasis (Table II).

Association of IL-35 plasma expression levels with the clinicopathological characteristics of patients with PCA. The IL-35 plasma concentrations of all the individuals with PCA are presented in Table II. The IL-35 concentration in the plasma of the individuals with Gleason scores of $\leq 6(82.07 \pm 18.92)$, $7(109.12 \pm 38.67)$ and $8-10(141.05 \pm 51.07 \mathrm{pg} / \mathrm{ml})$ were significantly different $(\mathrm{P}<0.0001$; Fig. 1B). The concentration of plasma IL-35 in patients with PCA, with Gleason scores of 7, was significantly higher compared with that in those with a Gleason score of $\leq 6(\mathrm{P}=0.0489)$. The concentration of plasma IL-35 in patients with PCA, with Gleason scores of 8-10, was significantly higher compared with that of $7(\mathrm{P}=0.0225)$ and the concentration of plasma IL-35 in patients with PCA with
Gleason scores of 8-10 was significantly higher compared with that of patients with a score of $\leq 6(\mathrm{P}=0.0009)$. The IL-35 plasma concentration was significantly increased in patients with PCA who were classified with TNM stage III-IV $(136.26 \pm 50.54 \mathrm{pg} / \mathrm{ml})$ compared with patients with TNM stage I-II (70.87 $\pm 15.26 \mathrm{pg} / \mathrm{ml} ; \mathrm{P}=0.0003$; Table II; Fig. 1C). The IL-35 plasma concentration in patients with PCA with lymph node metastasis was significantly increased compared with individuals without lymph node metastasis (170.48 \pm 37.49 vs. 97.73 \pm 38.14 pg/ml; P<0.0001; Table II; Fig. 1D). Similarly, the IL-35 plasma concentration was significantly increased in patients with PCA with distant metastasis compared with individuals without distant metastasis (164.64 \pm 42.15 vs. 92.53 \pm 32.77 pg/ml; P<0.0001; Table II; Fig. 1E).

Furthermore, the overall survival rate of patients with PCA with an increased IL-35 plasma concentration (greater than the median value of $127.49 \mathrm{pg} / \mathrm{ml} ; 42.0$ months) was significantly decreased compared with the patients with a decreased IL-35 plasma concentration (less than the median value; 63.9 months; $\mathrm{P}=0.0071$; log-rank test; Fig. 1F).

ROC curves of IL-35 and PSA expression levels in plasma. The AUC of IL-35 did not differ significantly compared with PSA in patients with PCA (AUC $=0.930$ vs. 0.919 ; $\mathrm{P}=0.5336$; Fig. 2A), and the sensitivity, specificity and diagnostic accuracy were $92.42,82.79$ and $86.17 \%$, respectively, at the best cut-off value of $70.99 \mathrm{pg} / \mathrm{ml}$. A significant difference was identified between IL-35 and PSA for the detection of PCA with lymph 
Table III. Expression of EBI3 and p35 in patients with prostate cancer with different clinicopathological characteristics.

\begin{tabular}{|c|c|c|c|c|c|c|c|}
\hline \multirow[b]{2}{*}{$\begin{array}{l}\text { Clinicopathological } \\
\text { characteristic }\end{array}$} & \multicolumn{4}{|c|}{ EBI3 expression } & \multicolumn{3}{|c|}{ p35 expression } \\
\hline & $\mathrm{n}$ & $\begin{array}{l}\text { Mean } \pm \text { standard } \\
\text { deviation }\end{array}$ & $\mathrm{t} / \mathrm{F}$-value & P-value & $\begin{array}{l}\text { Mean } \pm \text { standard } \\
\text { deviation }\end{array}$ & $\mathrm{t} / \mathrm{F}$-value & P-value \\
\hline Position & & & 2.863 & 0.0052 & & 2.850 & $0.0054^{\mathrm{a}}$ \\
\hline Cancer & 90 & $8.92 \pm 2.52$ & & & $6.47 \pm 2.67$ & & \\
\hline Adjacent to cancer & 90 & $7.87 \pm 2.94$ & & & $5.42 \pm 2.98$ & & \\
\hline Age, years & & & 0.357 & 0.305 & & 1.031 & 0.722 \\
\hline$<65$ & 21 & $9.10 \pm 2.36$ & & & $7.57 \pm 3.14$ & & \\
\hline$\geq 65$ & 69 & $8.87 \pm 2.58$ & & & $6.09 \pm 2.96$ & & \\
\hline Gleason score & & & $F=9.644$ & 0.0002 & & $\mathrm{~F}=9.300$ & $0.0002^{\mathrm{b}}$ \\
\hline$\leq 6$ & 29 & $7.38 \pm 2.67$ & & & $5.24 \pm 3.27$ & & \\
\hline 7 & 34 & $8.82 \pm 1.91$ & & & $6.47 \pm 2.21$ & & \\
\hline $8-10$ & 27 & $9.96 \pm 2.01$ & & & $7.93 \pm 1.96$ & & \\
\hline
\end{tabular}

${ }^{\mathrm{a}} \mathrm{P}<0.05$ and ${ }^{\mathrm{b}} \mathrm{P}<0.001 . \mathrm{EBI3}$, Epstein-barr virus-induced gene 3; $\mathrm{p} 35$, interleukin-12A.
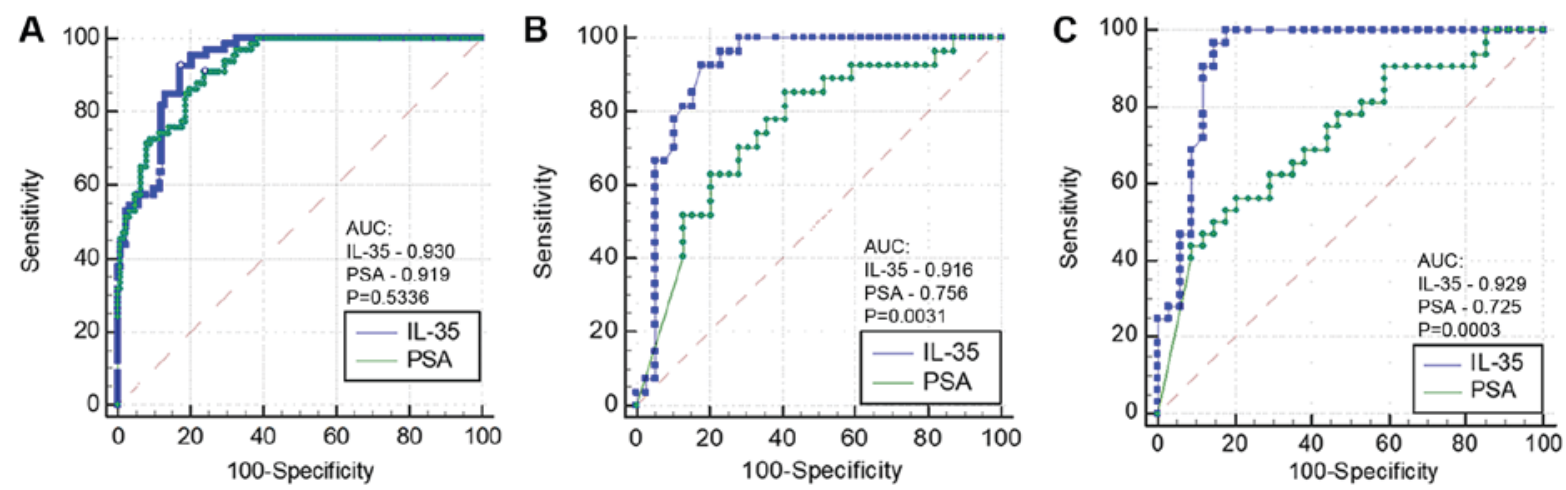

Figure 2. ROC curves of plasma IL-35 and PSA concentrations. (A) ROC curves of IL-35 and PSA for diagnosing prostate cancer. AUC=0.930 vs. 0.919 ; $\mathrm{P}=0.5336$. (B) ROC curves of IL-35 and PSA for determining the existence of lymph node metastasis. AUC $=0.916$ vs. 0.756; $\mathrm{P}=0.0031$. (C) ROC curves of IL-35 and PSA for determining the existence of distant metastasis. AUC=0.929 vs. 0.725; P=0.0003. IL-35, interleukin-35; PSA, prostate-specific antigen; ROC, receiver operating characteristic; AUC, area under the curve.

node metastasis (AUC=0.916 vs. 0.756; P=0.0031; Fig. 2B), and at the best cut-off value of $117.56 \mathrm{pg} / \mathrm{ml}$, the sensitivity, specificity and diagnostic accuracy of IL-35 were $92.59,82.05$ and $86.36 \%$, respectively. A statistically significant difference was observed between IL-35 and PSA in diagnosing PCA with distant metastasis (AUC=0.929 vs. 0.725; $\mathrm{P}=0.0003$; Fig. $2 \mathrm{C}$ ), and at the best cut-off value of $90.43 \mathrm{pg} / \mathrm{ml}$, the sensitivity, specificity and diagnostic accuracy of IL-35 were 100, 82.35 and $90.91 \%$, respectively.

IL-35 expression levels in prostate carcinoma tissues in patients with PCA. The protein expression levels of EBI3 and p35 were used as a proxy for determining the protein expression level of IL-35. A tissue microarray containing matched pairs of primary prostate carcinoma tissue and adjacent tissues from 90 patients was used for immunohistochemical analysis. A semi-quantitative method was used to detect the expression of EBI3 and $\mathrm{p} 35$ by measuring the density of positive staining. EBI3 and p35 expression was significantly increased in tumor tissues compared with the adjacent matching tissues, and positive staining was primarily localized to the cytoplasm and the nucleus (Fig. 3A-C; P<0.01; Table III). The extent of staining was divided into four grades: i) Negative, -; ii) low staining, +; iii) medium staining, ++; and iv) high staining, +++ (Fig. 3D). The final staining grades of EBI3 and P35 were correlated $(r=0.604 ; \mathrm{P}<0.0001$; Fig. 3E), as was the extent of staining of EBI3 and P35 ( $r=0.725$; $<<0.0001$; Fig. 3F). Similarly, EBI3 and P35 staining scores were associated with the Gleason score $(\mathrm{P}<0.001$; Fig. $3 \mathrm{G}$ and $\mathrm{H})$. As the Gleason score increased, the EBI3 and P53 staining scores additionally increased. The EBI3 staining scores of the PCA tissue with Gleason scores of 7 were significantly higher compared with those with a score of $\leq 6(\mathrm{P}=0.011)$. The EBI3 staining scores of the PCA tissue with Gleason scores of 8-10 were significantly higher compared with those with a score of $7(\mathrm{P}=0.049)$ and the EBI3 staining scores of the PCA tissue with Gleason scores of 8-10 was significantly higher compared with that in patients with a score of $\leq 6(\mathrm{P}<0.001)$. The $\mathrm{p} 35$ staining scores 
A

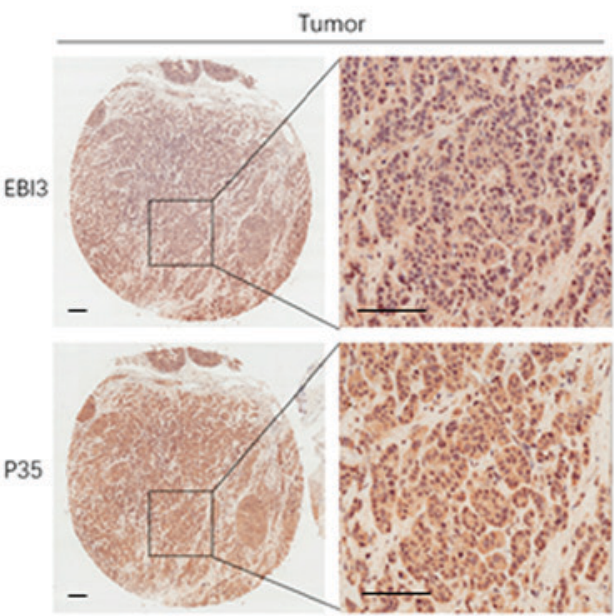

Adjacent tissue

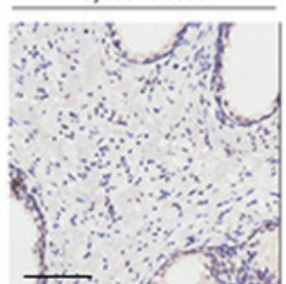

B
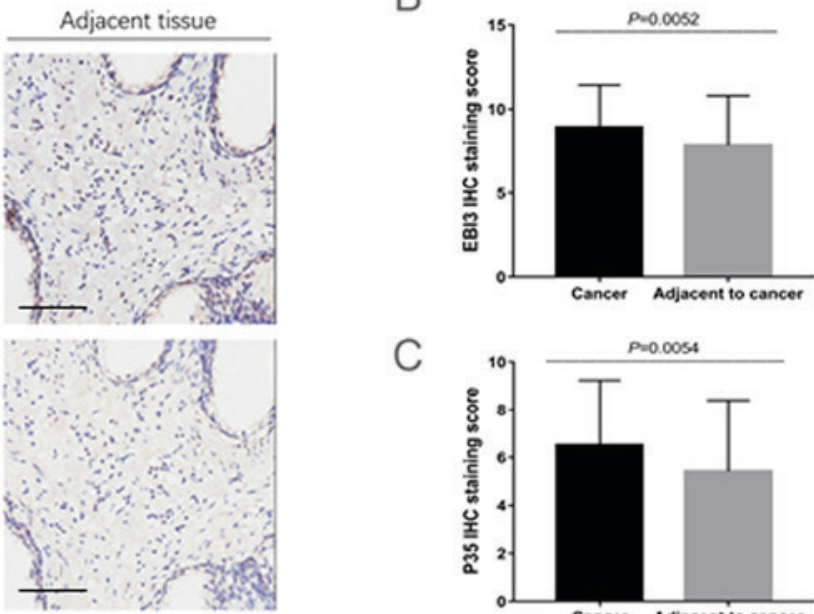

C

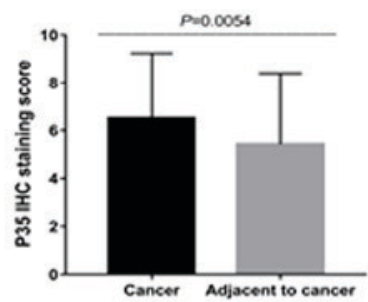

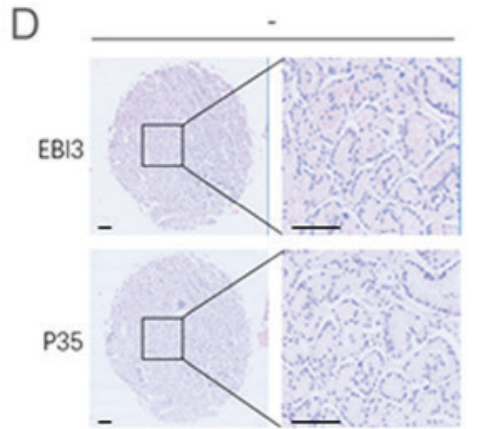

E

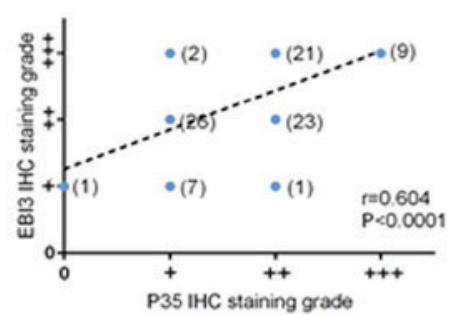

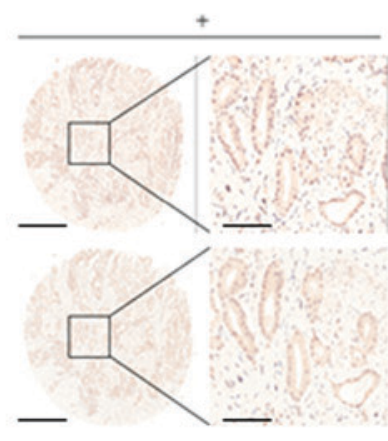

$\mathrm{F}$

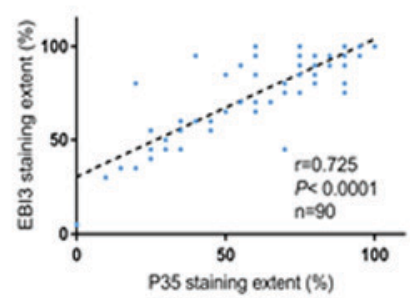

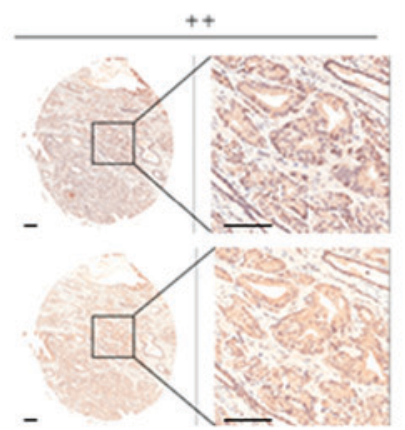

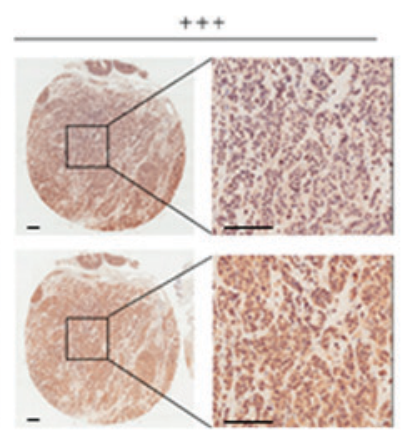

G

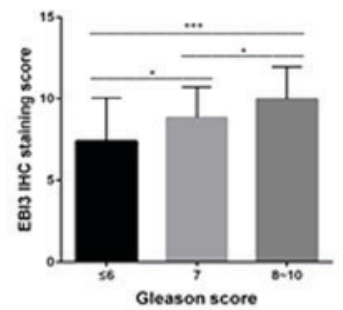

$\mathrm{H}$

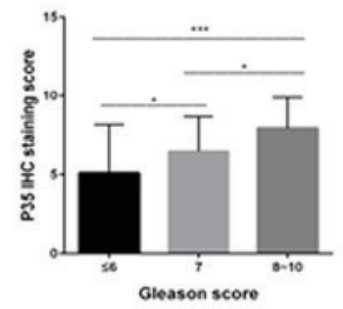

Figure 3. Expression of IL-35 in PCA tumor tissue. A human paraffin-embedded tissue microarray was used to analyze the protein expression levels of the two subunits of the IL-35 ligand (EBI3 and p35). (A) IHC staining and scoring of (B) EBI3 and (C) p35 proteins in PCA and the matching adjacent normal prostate tissues. Scale bar, $100 \mu \mathrm{m}$. (D) Representative images are presented for absent, low, medium and high expression of EBI3 and p35 using IHC staining in PCA tissues. Scale bar, $100 \mu \mathrm{m}$. (E) Spearman's rank correlation coefficient analysis of EBI3 and p35 expression in PCA. r=0.604. (F) Staining extent correlation analysis of EBI3 and p35. r=0.725; $\mathrm{P}<0.0001$. Association between expression of $(\mathrm{G}) \mathrm{EBI} 3$ and $(\mathrm{H}) \mathrm{p} 35$ with the Gleason scores. ${ }^{*} \mathrm{P}<0.05$ and ${ }^{* * *} \mathrm{P}<0.001$. IL, interleukin; PCA, prostate cancer; EBI, Epstein-barr virus-induced gene 3; p35, IL-12A; IHC, immunohistochemical.

of the PCA tissue with Gleason scores of 7 were significantly higher compared with that of $\leq 6(\mathrm{P}=0.030)$. The p35 staining scores of the PCA tissue with Gleason scores of 8-10 were significantly higher compared with those with a score of 7 $(\mathrm{P}=0.023)$, and the $\mathrm{p} 35$ staining scores of the PCA tissue with Gleason scores of 8-10 was significantly higher compared with that in patients with a score of $\leq 6(\mathrm{P}<0.001)$.

\section{Discussion}

Cytokines serve an important role in promoting malignant properties of cells, including tumor carcinogenesis, angiogenesis and metastasis in the tumor microenvironment (20). In addition to stromal cells and infiltrating immune cells, tumor cells produce and secrete various types of cytokines, among which, tumor necrosis factor- $\alpha$ (21), transforming growth factor- $\beta$ (22) and IL-6 (23) are well-studied. IL-35 is an important mediator involved in regulating the function of T-cells, which serve a potent immunosuppressive role, suppressing proliferation of T-cells and inducing their transformation into suppressive inducible regulatory $\mathrm{T}$ cells $\left(\mathrm{T}_{\text {regs }}\right)(24)$.

Based on the data in the present study, IL-35 may be associated with the tumorigenesis and progression of PCA. IL-35 plasma concentration was significantly increased in patients with PCA compared with patients with BPH or the healthy control group in agreement with a recent study (25). Plasma IL-35 expression levels in patients with PCA were significantly increased in patients with higher Gleason scores. Chatrabnous et al (26) recently demonstrated that the 
genetic variations of a single nucleotide polymorphism in the position of rs3761548, may have affected the susceptibility to PCA and plasma IL-35 concentration, although the study had a limitation of a small cohort. Furthermore, plasma IL-35 concentrations were positively associated with disease severity and clinical stage of tumors in patients with PCA, which was additionally demonstrated in colorectal cancer (7), renal cell carcinoma (9) and nasopharyngeal carcinoma (27), suggesting that this cytokine may be derived from tumors and may be regarded as a valuable biomarker for evaluating tumor progression.

In the present study, IL-35 protein expression levels in tumor tissues and matching adjacent non-tumor tissues of patients with PCA were detected, and the association between IL-35 in PCA tissue and the Gleason score was analyzed. Co-expression of the two subunits of IL-35 (EBI3 and p35) was used to determine the IL-35 expression levels. EBI3 and p35 protein expression levels in PCA tissues were highly correlated, thus, suggesting their existence in PCA primarily as IL-35. The protein expression level of IL-35 in the intra-tumoral zone was significantly increased compared with the peritumoral zone. The Gleason score was associated with the protein expression level of IL-35, and the plasma IL-35 concentration in patients with Gleason scores of 8-10 were significantly increased compared with patients with a Gleason scores of $\leq 6$ and 7. Previous studies demonstrated that expression of the p35 and EBI3 subunits was increased in a number of tumor tissues, including PDAC (28) and colorectal cancer (7). In addition, elevated plasma IL-35 concentration and increased expression of IL-35 in tumor tissues were associated with immunosuppression and regarded as an unfavorable prognostic factor (28).

Furthermore, increased plasma IL-35 protein expression levels may serve an important role in metastasis of PCA. The IL-35 concentration in the plasma of patients with PCA with lymph nodes metastasis was significantly increased compared with patients with no evidence of lymph nodes metastasis. Similarly, in patients with PCA with distant metastasis, IL-35 plasma expression levels were significantly increased compared with patients with no evidence of distant metastasis. IL-35 may promote the metastasis of PCA, a role that was recently demonstrated in liver (16), breast (13) and pancreatic cancer (28). In addition, IL-35 may be a more suitable biomarker compared with PSA in diagnosing PCA with lymph nodes or distant metastasis.

Tumor growth and metastasis is a complicated process involving multiple steps. At present, the mechanism of IL-35 promoting tumor development and metastasis has not yet been determined. Huang et al (29) suggested that tumor-derived IL-35 increases the microvessel density in tumor tissues of PDAC. In a xenograft mouse model, IL-35 increased the recruitment of monocytes into PDAC tumors, which required $\mathrm{C}-\mathrm{C}$ motif chemokine ligand 5. Upon exposure to IL-35, monocytes increased the expression of $\mathrm{C}-\mathrm{X}-\mathrm{C}$ motif chemokine ligand (CXCL) 1 and CXCL8 genes whose products promoted angiogenesis (29). Turnis et al (30) observed substantial enrichment of $\mathrm{IL}^{-35^{+}} \mathrm{T}_{\text {reg }}$ cells in tumors, and demonstrated that treatment with an IL-35-specific antibody or restrictive deletion of $\mathrm{T}_{\mathrm{reg}}$ cells limited the growth of tumors in multiple murine models of human cancer. $\mathrm{T}_{\text {reg }}$-cell-derived IL-35 promoted the expression of multiple inhibitory receptors, including programmed cell death protein 1, T-cell immunoglobulin mucin receptor 3 and lymphocyte activation gene 3 protein, thereby facilitating the exhaustion of intra-tumoral T-cells (30).

At present, the molecular mechanism of IL-35 promoting tumor development has not yet been determined. Previous studies demonstrated the role of IL-35 in the transformation of murine and human $\mathrm{CD}^{+} / \mathrm{CD} 25^{-} \mathrm{T}$-cells into IL-35-induced $\mathrm{T}_{\text {reg }}$ cells $(24,31)$. Recently, Wang et al (32) demonstrated that the number of IL-35-producing B-cells was significantly increased in patients with advanced gastric cancer, and that the frequency of IL-35-producing B-cells was associated with the frequencies of $\mathrm{T}_{\text {reg }}$ cells, myeloid derived suppressor cells, IL-10-producing B-cells and $\mathrm{CD} 14^{+}$monocytes in the patients with gastric cancer.

Previous studies suggested that IL-35 recruited and activated specific members of the signal transducer and activator of transcription (STAT) family of transcription factors and mediated their biological activities by binding to the IL-35 receptor $(33,34)$. The IL-35 receptors in mice were demonstrated to be comprised of IL-12R $\beta 2$ and membrane glycoprotein 130 (gp130) subunits on T cells (35), or the IL-27R $\alpha$ subunit on B-cells (36). These differences may explain the diversity of downstream responses of STAT activation observed in $\mathrm{T}$ and B-cells in mice. Ma et al (37) demonstrated that STAT1 and STAT3 may be activated by IL-35 in human CD4 ${ }^{+}$T-cells during incubation and following temporary stimulation. However, STAT1 and STAT3 were not activated by IL-35 in B-cells following temporary stimulation, as IL-35R was not constitutively expressed in human B-cells. Huang et al (29) demonstrated that IL-35 activated transcription of genes whose products promote angiogenesis by inducing gp130 signaling, through IL12R $\beta 2$, and phosphorylation of STAT1 and STAT4, in cells and mice with xenograft tumors (29).

However, the present study has certain limitations. Only a relatively small number of clinical samples were retrospectively analyzed. A prospective analysis of a larger number of samples is required to demonstrate the clinical significance of IL-35 prior to examining the clinical significance. The majority of the patients in the present study presented with high-stage PCA. The majority of the patients with cancer in China, particularly in rural areas, present with local invasion or metastasis when they are diagnosed, which is different from European and American countries. This may lead to a statistical bias. Since no conformational antibodies specific to IL-35 are available at present, the co-expression of EBI3 and p35 was detected for the IHC staining. This method is inconvenient to use, and the result is somewhat indirect. The functional role of increased protein expression levels of IL-35 in patients with PCA in tumor progression has not yet been determined, and requires further investigation.

In summary, IL-35 expression was increased in the plasma and tumors in patients with PCA. The plasma IL-35 concentration was associated with advanced stage PCA, suggesting that IL-35 may promote the tumorigenesis and progression of PCA. IL-35 may be an important biomarker for determining the presence and progression of cancer in patients with PCA and may additionally serve as a novel therapeutic target for PCA. 


\section{Acknowledgements}

Not applicable.

\section{Funding}

The present study was funded by The National Natural Science Foundation of China (grant nos. 81501568 and 81471761).

\section{Availability of data and materials}

The datasets used and analyzed during the present study are available from the corresponding author on reasonable request.

\section{Authors' contributions}

ZG, JZ and XY conceived and designed the present study. JZ, YW and HZ performed the experiments. JZ and XY wrote the manuscript. ZG reviewed and edited the manuscript. All authors read and approved the final manuscript.

\section{Ethics approval and consent to participate}

The present study was approved by The Medical Ethics Committee of Tianjin Medical University Cancer Institute and Hospital (Tianjin, China). All the procedures performed in the present study involving human participants were in accordance with the ethical standards of The Institutional and National Research Committee and with The 1964 Helsinki Declaration and its later amendments or comparable ethical standards. Informed consent was obtained from all individual participants included in the present study.

\section{Patient consent for publication}

Not applicable.

\section{Competing interests}

The authors declare that they have no competing interests.

\section{References}

1. Bray F, Ferlay J, Soerjomataram I, Siegel RL, Torre LA and Jemal A: Global cancer statistics 2018: GLOBOCAN estimates of incidence and mortality worldwide for 36 cancers in 185 countries. CA Cancer J Clin 68: 394-424, 2018.

2. Lilja H, Ulmert D and Vickers AJ: Prostate-specific antigen and prostate cancer: Prediction, detection and monitoring. Nat Rev Cancer 8: 268-278, 2008.

3. Shariat SF, Semjonow A, Lilja H, Savage C, Vickers AJ and Bjartell A: Tumor markers in prostate cancer I: Blood-based markers. Acta Oncol 50 (Suppl 1): S61-S75, 2011.

4. Hwang JE, Joung JY, Shin SP, Choi MK, Kim JE, Kim YH, Park WS, Lee SJ and Lee KH: Ad5/35E1aPSESE4: A novel approach to marking circulating prostate tumor cells with a replication competent adenovirus controlled by PSA/PSMA transcription regulatory elements. Cancer Lett 372: 57-64, 2016.

5. Cooperberg MR, Broering JM and Carroll PR: Time trends and local variation in primary treatment of localized prostate cancer. J Clin Oncol 28: 1117-1123, 2010.

6. Collison LW, Chaturvedi V, Henderson AL, Giacomin PR, Guy C, Bankoti J, Finkelstein D, Forbes K, Workman CJ, Brown SA, et al: IL-35-mediated induction of a potent regulatory T cell population. Nat Immunol 11: 1093-1101, 2010.
7. Zeng JC, Zhang Z, Li TY, Liang YF, Wang HM, Bao JJ, Zhang JA, Wang WD, Xiang WY, Kong B, et al: Assessing the role of IL-35 in colorectal cancer progression and prognosis. Int J Clin Exp Pathol 6: 1806-1816, 2013.

8. Jin P, Ren H, Sun W, Xin W, Zhang H and Hao J: Circulating IL-35 in pancreatic ductal adenocarcinoma patients. Hum Immunol 75: 29-33, 2014.

9. Jin L, Xu X, Ye B, Pan M, Shi Z and Hu Y: Elevated serum interleukin-35 levels correlate with poor prognosis in patients with clear cell renal cell carcinoma. Int J Clin Exp Med 8: 18861-18866, 2015

10. Wu W, Jiang H, Li Yi and Yan MX: IL-35 expression is increased in laryngeal squamous cell carcinoma and in the peripheral blood of patients. Oncol Lett 13: 3303-3308, 2017.

11. Wang Z, Liu JQ, Liu Z, Shen R, Zhang G, Xu J, Basu S, Feng Y and Bai X: Tumor-derived IL-35 promotes tumor growth by enhancing myeloid cell accumulation and angiogenesis. J Immunol 190: 2415-2423, 2013.

12. Nicholl MB, Ledgewood CL, Chen XH, Bai Q, Qin CL, Cook KM, Herrick EJ, DiazArias A, Moore BJ and Fang YJ: IL-35 promotes pancreas cancer growth through enhancement of proliferation and inhibition of apoptosis: Evidence for a role as an autocrine growth factor. Cytokine 70: 126-133, 2014.

13. Zhao Z, Chen X, Hao SN, Jia R, Wang N, Chen S, Li M, Wang C and Mao H: Increased interleukin-35 expression in tumor-infiltrating lymphocytes correlates with poor prognosis in patients with breast cancer. Cytokine 89: 76-81, 2017.

14. Tao Q, Pan Y, Wang Y, Wang H, Xiong S, Li Q, Wang J, Tao L, Wang Z, Wu F, et al: Regulatory T cells derived IL-35 promotes the growth of adult acute myeloid leukemia blasts. Int J Cancer 137: 2384-2393, 2015.

15. Gu X, Tian T, Zhang B, Liu Y, Yuan C, Shao LJ, Guo Y and Fan K: Elevated plasma interleukin-35 levels predict poor prognosis in patients with non-small cell lung cancer. Tumour Biol 36: 2651-2656, 2015.

16. Fu YP, Yi Y, Cai XY, Sun J, Ni XC, He HW, Wang JX, Lu ZF, Huang JL, Cao Y, et al: Overexpression of interleukin-35 associates with hepatocellular carcinoma aggressiveness and recurrence after curative resection. Br J Cancer 114: 767-776, 2016.

17. Fan YG, Zhai JM, Wang W, Feng B, Yao GL, An YH and Zeng Chao: IL-35 over-expression is associated with genesis of gastric cancer. Asian Pac J Cancer Prev 16: 2845-2849, 2015.

18. Buyyounouski MK, Choyke PL, McKenney JK, Sartor O, Sandler HM, Amin MB, Kattan MW and Lin DW: Prostate cancer-major changes in the American Joint Committee on Cancer eighth edition cancer staging manual. CA Cancer J Clin 67: 245-253, 2017.

19. Epstein JI, Egevad L, Amin MB, Delahunt B, Srigley JR and Humphrey PA; Grading Committee: The 2014 International Society of Urological Pathology (ISUP) Consensus Conference on Gleason Grading of prostatic carcinoma: Definition of grading patterns and proposal for a new grading system. Am J Surg Pathol 40: 244-252, 2016.

20. Whiteside TL: The tumor microenvironment and its role in promoting tumor growth. Oncogene 27: 5904-5912, 2008.

21. Salomon BL, Leclerc M, Tosello J, Ronin E, Piaggio E and Cohen JL: Tumor necrosis factor $\alpha$ and regulatory T cells in oncoimmunology. Front Immunol 9: 444, 2018.

22. Vivekanandhan S and Mukhopadhyay D: Genetic status of KRAS influences transforming growth factor-beta (TGF- $\beta$ ) signaling: An insight into Neuropilin-1 (NRP1) mediated tumorigenesis. Semin Cancer Biol 54: 72-79, 2019.

23. Huang S, Liu Q, Liao Q, Wu Q, Sun B, Yang Z, Hu X, Tan M and Li L: Interleukin-6/signal transducer and activator of transcription 3 promotes prostate cancer resistance to androgen deprivation therapy via regulating pituitary tumor transforming gene 1 expression. Cancer Sci 109: 678-687, 2018.

24. Seyerl M, Kirchberger S, Majdic O, Seipelt J, Jindra C, Schrauf C and Stöckl J: Human rhinoviruses induce IL-35-producing Treg via induction of B7-H1 (CD274) and sialo adhesin (CD169) on DC. Eur J Immunol 40: 321-329, 2010.

25. Zhou C, Zhang J, Chen Y, Wang H and Hou J: Interleukin-35 as a predictor of prostate cancer in patients undergoing initial prostate biopsy. Onco Targets Ther 10: 3485-3491, 2017.

26. Chatrabnous N, Ghaderi A, Ariafar A, Razeghinia M S, Nemati $M$ and Jafarzadeh A: Serum concentration of interleukin-35 and its association with tumor stages and FOXP3 gene polymorphism in patients with prostate cancer. Cytokine 113: 221-227, 2019. 
27. Zhang Y, Sun $\mathrm{H}$, Wu H, Tan QD and Xiang K: Interleukin 35 is an independent prognostic factor and a therapeutic target for nasopharyngeal carcinoma. Contemp Oncol (Pozn) 2: 120-124, 2015.

28. Huang C, Li N, Li Z, Chang A, Chen Y, Zhao T, Li Y, Wang X, Zhang W, Wang Z, et al: Tumour-derived Interleukin 35 promotes pancreatic ductal adenocarcinoma cell extravasation and metastasis by inducing ICAM1 expression. Nat Commun 8: 14035, 2017.

29. Huang C, Li Z, Li N, Li Y, Chang A, Zhao T, Wang X, Wang H, Gao S, Yang S, et al: Interleukin 35 expression correlates with microvessel density in pancreatic ductal adenocarcinoma, recruits monocytes, and promotes growth and angiogenesis of Xenograft tumors in mice. Gastroenterology 154: 675-688, 2018.

30. Turnis ME, Sawant DV, Szymczak-Workman AL, Andrews LP, Delgoffe GM, Yano H, Beres AJ, Vogel P, Workman CJ and Vignali DA: Interleukin-35 limits anti-tumor immunity. Immunity 44: 316-329, 2016

31. Hanahan D and Weinberg RA: Hallmarks of cancer: The next generation. Cell 144: 646-674, 2011.

32. Wang K, Liu J and Li J: IL-35-producing B cells in gastric cancer patients. Medicine (Baltimore) 97: e0710, 2018.

33. Trinchieri G, Pflanz S and Kastelein RA: The IL-12 family of heterodimeric cytokines: New players in the regulation of T cell responses. Immunity 19: 641-644, 2003.
34. Sun L, He C, Nair L, Yeung $\mathrm{J}$ and Egwuagu CE: Interleukin 12 (IL-12) family cytokines: Role in immune pathogenesis and treatment of CNS autoimmune disease. Cytokine 75: 249-255, 2015.

35. Collison LW, Delgoffe GM, Guy CS, Vignali KM, Chaturvedi V, Fairweather D, Satoskar AR, Garcia KC, Hunter CA, Drake CG, et al: The composition and signaling of the IL-35 receptor are unconventional. Nat Immunol 13: 290-299, 2012

36. Wang RX, Yu CR, Dambuza IM, Mahdi RM, Dolinska MB, Sergeev YV, Wingfeld PT, Kim SH and Egwuagu CE: Interleukin-35 induces regulatory B cells that suppress autoimmune disease. Nat Med 20: 633-641, 2014.

37. Ma YH, Chen L, Xie G, Zhou Y, Yue C, Yuan X, Zheng Y, Wang W, Deng L and Shen L: Elevated level of Interleukin-35 in colorectal cancer induces conversion of T cells into iTr35 by activating STAT1/STAT3. Oncotarget 7: 73003-73015, 2016.

cc) (i) $\ominus$ This work is licensed under a Creative Commons Attribution-NonCommercial-NoDerivatives 4.0 International (CC BY-NC-ND 4.0) License. 